Pesq. Vet. Bras. 35(5):448-450, maio 2015

DOI: $10.1590 / \mathrm{S} 0100-736 \mathrm{X} 2015000500010$

\title{
Intoxicação por Metternichia princeps (Solanaceae) em caprinos no Estado da Bahia ${ }^{1}$
}

\author{
Pedro M.O. Pedroso ${ }^{2 *}$, Maria V.B. Santos², Visakha G. Seus², Reanne M.M. da Silva², \\ Franklin Riet-Correa ${ }^{3}$ e Juliana T.S.A. Macêdo ${ }^{2}$
}

\begin{abstract}
Pedroso P.M.O., Santos M.V.B., Seus V.G., Silva R.M.M., Riet-Correa F. \& Macêdo J.T.S.A. 2015. [Poisoning by Metternichia princeps (Solanaceae) in goats in the State of Bahia, Brazil.] Intoxicação por Metternichia princeps (Solanaceae) em caprinos no Estado da Bahia. Pesquisa Veterinária Brasileira 35(5):448-450. Setor de Patologia Veterinária, Universidade Federal do Recôncavo da Bahia, Campus Universitário, Rua Rui Barbosa 710, Cruz das Almas, BA 44380-000, Brazil. E-mail: pedrosovet@yahoo.com.br

An outbreak of poisoning by Metternichia princeps is reported in goats from the State of Bahia. Out of eight goats three showed symptoms of poisoning and died; on two of them post-mortem examinations were performed. The main clinical signs were nasal mucous secretion, weight loss, diarrhea, lethargy, mild weakness, staggering gait, flexion of the fore and hind limbs, sternal recumbence, and lateral recumbence followed by death after approximately two days of clinical manifestations. The serum concentration of urea and creatinine and the serum activities of creatine phosphokinase were increased. At necropsy pulmonary edema, hydrothorax, hydropericardium, ascites, pale kidneys, perirenal edema and hemorrhages in the subcutaneous tissue were observed. Microscopically the kidneys showed accentuated coagulation necrosis of the tubular epithelium and tubules and epithelial regeneration. In the lungs there was accentuated congestion associated with interalveolar and interseptal edema.
\end{abstract}

INDEX TERMS: Poisonous plants, Metternichia princeps, Solanaceae, nephrosis, pulmonary edema, ruminant, plant poisoning, Northeastern Brazil.

RESUMO.- Descreve-se um surto de intoxicação por Metternichia princeps em caprinos no Estado da Bahia. De oito caprinos, três morreram, dos quais dois foram necropsiados; cinco não adoeceram. Os principais sinais clínicos caracterizaram-se por secreção nasal mucosa, emagrecimento, diarreia, apatia, debilidade leve, andar cambaleante, flexão dos membros torácicos e pélvicos, decúbito esterno-abdominal e decúbito lateral, seguidos de morte após aproximadamente dois dias de evolução clínica. Na necropsia foi observado edema pulmonar, hidrotórax, hidropericárdio, ascite, rins pálidos, edema perirrenal e hemorragias no tecido subcutâneo. Microscopicamente nos rins havia acen-

\footnotetext{
${ }^{1}$ Recebido em 1 de maio de 2015.

Aceito para publicação em 20 de maio de 2015

${ }^{2}$ Setor de Patologia Veterinária, Hospital Universitário de Medicina Veterinária, Universidade Federal do Recôncavo da Bahia (UFRB), Rua Rui Barbosa 710, Campus Universitário, Cruz das Almas, BA 44380-000, Brasil. *Autor para correspondência: pedrosovet@yahoo.com.br

${ }^{3}$ Hospital Veterinário, Centro de Saúde e Tecnologia Rural (CSTR), Campus de Patos, Universidade Federal de Campina Grande (UFCG), Patos, PB 58700-000, Brasil.
}

tuada necrose de coagulação do epitélio tubular e túbulos com regeneração do epitélio. No pulmão havia acentuada congestão associada a edema interalveolar e interseptal. Na bioquímica sanguínea observou-se aumento na ureia, creatinina e creatinina fosfoquinase.

TERMOS DE INDEXAÇÃO: Plantas tóxicas, Metternichia princep, Solanaceae, nefrose, edema pulmonar, ruminante, intoxicação por plantas.

\section{INTRODUÇÃO}

Metternichia princeps, árvore da família Solanaceae, é popularmente conhecida como "trombeteira", "café-do-mato" e "jasmim-do-morro" (Lorenzi 2009, Tokarnia et al. 2012). Casos de intoxicação espontânea só foram registrados em caprinos no Estado do Rio de Janeiro (Caldas et al. 2011). Experimentalmente a intoxicação foi reproduzida em caprinos, bovinos, ovinos e coelhos (Caldas et al. 2012, Maran et al. 2012, Prado et al. 2012). Os principais sinais clínicos incluem dificuldade de locomoção, incapacidade de se manter em estação, prostração e decúbito, seguidos de morte. As alterações macroscópicas são observadas es- 
pecialmente nos rins, que ficam pálidos e com estriações esbranquiçadas do córtex até a região medular. Microscopicamente é observado necrose de coagulação dos túbulos uriníferos (Tokarnia et al. 2012). 0 objetivo do presente trabalho foi descrever os achados epidemiológicos e clínico-patológicos de um surto de intoxicação por $M$. princeps em caprinos no Estado da Bahia.

\section{MATERIAL E MÉTODOS}

O surto ocorreu em novembro de 2012 em uma propriedade rural de criação semi-extensiva de caprinos localizada no município de Cruz das Almas, região do Recôncavo da Bahia. Amostras da planta fornecida no local foram identificadas pelo Dr. Alessandro Rapini do Departamento de Biologia da Universidade Estadual de Feira de Santana, Bahia, como Metternichia princeps (Fig.1). Dados epidemiológicos e histórico clínico foram obtidos através do tratador. De oito caprinos, cinco não adoeceram e três morreram, dos quais dois foram necropsiados (Caprinos 1 e 2). Na necropsia foram coletados fragmentos de órgãos da cavidade abdominal, cavidade torácica e sistema nervoso central e fixados em formol $10 \%$, processados de forma rotineira para histologia e coradas pela hematoxilina e eosina (HE). Urina do Caprino 1 foi coletada para exame físico e químico. Adicionalmente amostras de sangue do Caprino 2 foram coletadas para realização de provas de função renal, hepática e dosagens de minerais.

\section{RESULTADOS}

O surto ocorreu após o corte e fornecimento de Metternichia princeps aos animais. Os caprinos eram da raça Parda Alpina, idade média de um ano e todos machos. Três dias após o consumo da planta os animais começaram a apresentar secreção nasal mucosa, emagrecimento, diarreia, apatia, debilidade leve, andar cambaleante, flexão dos membros torácicos e pélvicos, decúbito esterno-abdominal, decúbito lateral e morte após aproximadamente dois dias de evolução clínica. Os valores laboratoriais revelaram: aspartato amino transferase 95,0 UI/L (VR: 43,0-132,0 UI/L); alanino aminotransferase 8,0 UI/L (VR: 43,0-132,0 UI/L); creatinina fosfoquinase 3.612,0 U/L (VR: 0,8-8,9 U/L); fósforo $3,0 \mathrm{mg} / \mathrm{dL}$ (VR: 6,5mg/dL); cálcio 8,2mg/dL $(8,9-11,7 \mathrm{mg} /$ $\mathrm{dL}$ ); ureia $218,0 \mathrm{mg} / \mathrm{dL}$ (VR:21,4-42,8mg/dL) e creatinina 9,0mg/dL (VR: 1,0-1,8mg/dL). 0 exame químico da urina

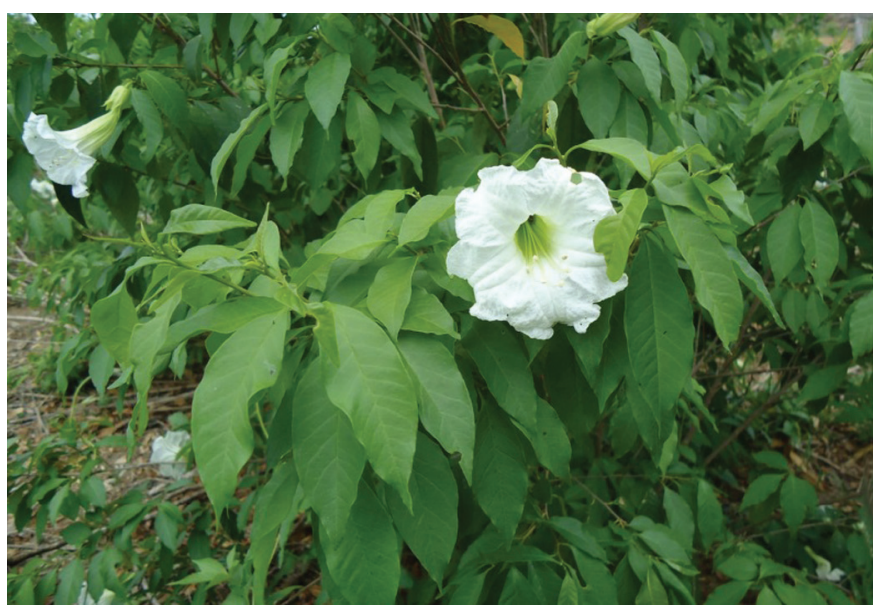

Fig.1. Detalhe das folhas e da flor de Metternichia princeps.

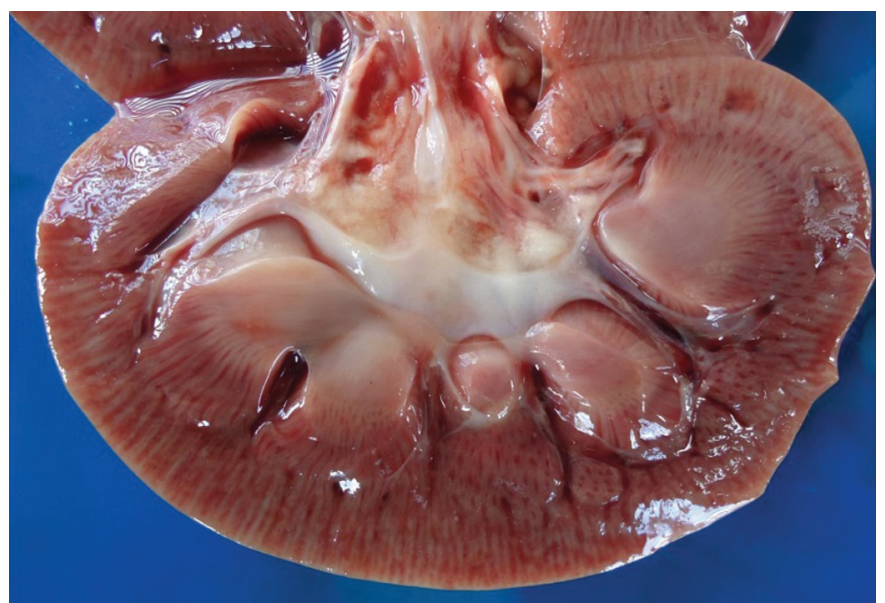

Fig.2. Rim de caprino intoxicado por Metternichia princeps mostrando superfície de corte com estriações pálidas.

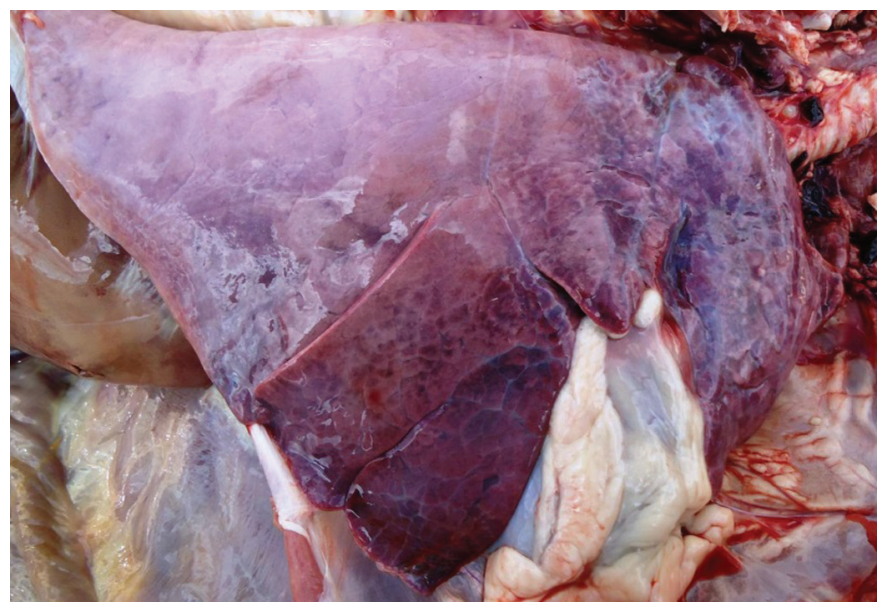

Fig.3. Observa-se congestão e edema pulmonar na intoxicação por Metternichia princeps em caprinos.

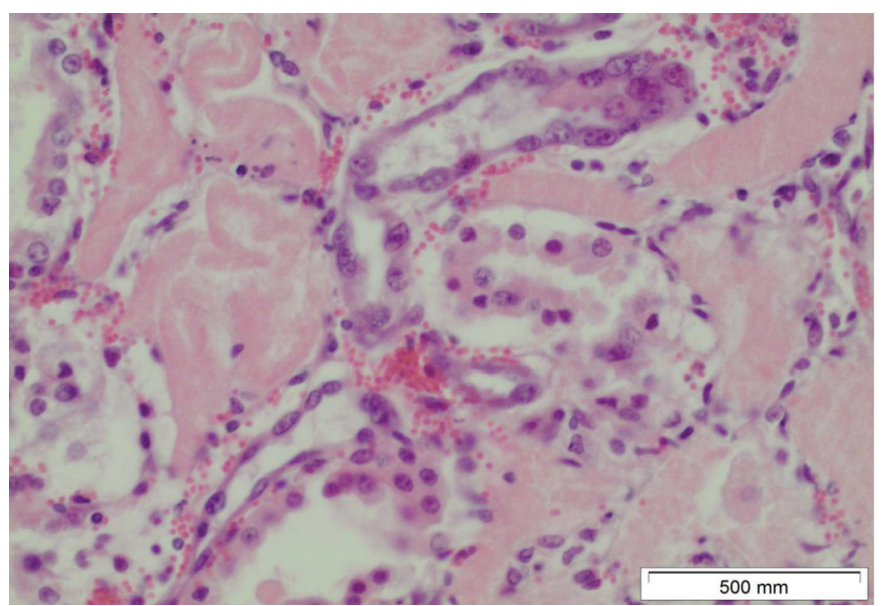

Fig.4. Rim. Observa-se necrose de coagulação acentuada do epitélio tubular na intoxicação por Metternichia princeps em caprinos. HE, obj.10x.

do Caprino 1 revelou a presença de proteínas e glicose em nível moderado.

Na necropsia dos dois caprinos, as principais alterações macroscópicas observadas foram nos rins, que se apresen- 
tavam pálidos, e ao corte com estriações esbranquiçadas desde a região cortical à medular (Fig.2). Outras alterações foram congestão e edema pulmonar acentuado (Fig.3), hidrotórax, hidropericárdio, ascite, edema perirrenal e da pelve renal, edema no mesentério e hemorragias no tecido subcutâneo.

As principais alterações microscópicas foram observadas nos rins e nos pulmões. Na região dos rins havia acentuada necrose de coagulação do epitélio tubular (Fig.4), além da presença de cilindros granulosos, hialinos e túbulos com regeneração do epitélio. No pulmão havia acentuada congestão de capilares alveolares associada a edema interalveolar e interseptal, além de discreto infiltrado inflamatório composto por macrófagos e neutrófilos no interstício.

\section{DISCUSSÃO}

O diagnóstico de intoxicação por Metternichia princeps em uma propriedade de criação de caprinos no Estado da Bahia foi baseado nos dados epidemiológicos, sinais clínicos, alterações patológicas e na bioquímica sanguínea. A planta encontra-se distribuída desde o Estado do Rio de Janeiro até a Bahia, especialmente na Mata Atlântica (Tokarnia et al. 2012). Após esse surto, a planta foi identificada nos municípios de Baixa Grande, Itaberaba e Entre Rios, região semiárida da Bahia. Até então, registros de intoxicação por M. princeps somente ocorreram em caprinos no Estado do Rio de Janeiro entre os anos de 2007 e 2009, introduzidos pela primeira vez em áreas na qual têm a planta (Prado et al. 2012).

O quadro clínico apresentado pelos caprinos foi semelhante aos casos de intoxicação espontânea e experimental por M. princeps em caprinos. A evolução deste surto foi semelhante à evolução da intoxicação experimental, uma vez que os animais ingeriram a planta num curto espaço de tempo, pelo fornecimento no cocho, enquanto que em casos de intoxicação espontânea, normalmente os animais ingerem a planta num espaço de tempo mais longo (Prado et al., 2012).

Na bioquímica sanguínea do único caprino analisado, os níveis de ureia e creatinina estavam acentuadamente aumentados. 0 aumento sérico de ureia e creatinina indica insuficiência renal (Kerry 2003). 0 nível elevado de creatinina fosfoquinase pode estar relacionado à lesão muscular decorrente do decúbito prolongado. Não se conhece ainda o princípio tóxico de $M$. princeps responsável pela nefrose e insuficiência renal.

A partir de casos espontâneos e experimentais, verificou-se que em caprinos, ovinos e bovinos predominam as alterações renais, enquanto que na reprodução experimental em coelhos observaram-se alterações cardíacas e hepáticas (Caldas et al. 2012, Maran et al. 2012, Prado et al. 2012, Tokarnia et al. 2012). Em experimentos realizados em bovinos e ovinos o quadro clínico-patológico foi semelhante aos observados nos caprinos (Caldas et al. 2012). Os achados patológicos nos caprinos deste estudo caracterizaram-se principalmente por alterações renais e pulmonares. Os rins apresentavam-se pálidos, e ao corte com estriações de coloração esbranquiçada desde a região cortical à medular; na histologia observou-se necrose de coagulação dos túbulos uriníferos (Tokarnia et al. 2012). Novos aspectos referentes à intoxicação por $M$. princeps foram observados nos pulmões dos dois caprinos que apresentavam edema e congestão, uma vez que, em estudo de Prado et al. (2012) não foram observadas alterações pulmonares nos caprinos. Na insuficiência renal o edema pulmonar pode estar relacionado com o aumento da permeabilidade dos capilares alveolares, como também ocorre em consequência de hipoproteinemia (Serakides et al. 2004). Além dessas duas lesões principais, ficou evidenciado edema perirrenal e edemas localizados nos dois animais necropsiados neste trabalho. Na intoxicação por Amaranthus spp., outra planta nefrotóxica, os edemas perirrenais e edemas localizados nas regiões adjacentes devem-se, provavelmente, à obstrução tubular por células necróticas com retrodifusão de líquido para o interstício (Lemos et al. 1993).

É importante considerar o diagnóstico diferencial com a intoxicação por outras plantas que causam alterações nefrotóxicas como Thiloa glaucocarpa (Combretaceae) e diversas espécies do gênero Amaranthus (Amaranthaceae), no entanto, no Brasil, essas plantas têm sido descritas causando intoxicação somente em bovinos (Tokarnia et al. 2012).

Neste trabalho o fator desencadeante da intoxicação foi o corte e o fornecimento acidental da planta aos animais, a pesar desta situação, deve-se considerar M. princeps como planta nefrotóxica para caprinos no Estado da Bahia.

Agradecimentos.- Os autores agradecem ao Dr. Alessandro Rapini pela identificação botânica. À Fundação de Amparo à Pesquisa do Estado da Bahia (FAPESB) (Proc. no 1431140005139) e ao INCT para o controle das intoxicações por plantas/CNPq (Proc. no 573534/2008-0).

\section{REFERÊNCIAS}

Caldas S.A., Brito M.F., Prado J.S., Yamasaki E.M., Veronezi L., Jönck F., Maia D.S. \& Tokarnia C.H. 2012. Intoxicação experimental por Metternichia princeps (Solanaceae) em ovinos e bovinos. Pesq. Vet. Bras. 32:10231029.

Kerr M.G. 2003. Avaliação com base em órgãos individuais, p.239-249. In: Ibid. (Ed.), Exames Laboratoriais em Medicina Veterinária: bioquímica clínica e hematologia. Roca, São Paulo.

Lemos R.A., Barros C.S.L., Salles M.S., Barros S.S. \& Peixoto P.V. 1993. Intoxicação espontânea por Amaranthus spinosus (Amaranthaceae) em bovinos. Pesq. Vet. Bras. 13:25-34.

Lorenzi H. 2009. Árvores Brasileiras: manual de identificação e cultivo de plantas arbóreas nativas do Brasil. Vol.3. Instituto Plantarum, Nova Odessa, SP. 368p.

Maran N.B., Caldas S.A., Prado J.S, Gomes A.D., Tokarnia C.H. \& Brito M.F. 2012. Intoxicação experimental por Metternichia princeps (Solanaceae) em coelhos Pesq. Vet. Bras. 32:872-880.

Prado J.S., Brito M.B., Caldas S.A., Yamasak E.M., Barbosa J.D., Maia D.S. \& Tokarnia C.H. 2012. Intoxicação natural e experimental por Metternichia princeps (Solanaceae) em caprinos. Pesq. Vet. Bras. 32:903-911.

Serakides R. 2004. Caderno didático de Patologia Veterinária. FEPMVZ-Editora, Belo Horizonte, MG, 215p.

Tokarnia C.H., Brito M.F., Barbosa J.D., Peixoto P.V. \& Döbereiner J. 2012. Plantas tóxicas do Brasil para animais de produção. Editora Helianthus, Rio de Janeiro, RJ, p.305-348. 